\title{
Coloration Defects in Industrial-Grade Zirconium Sponge
}

\author{
Micah Eastman $^{1}$ and Jun Jiao ${ }^{1,2}$ \\ 1. Portland State University, Department of Physics, Portland OR, USA \\ 2. Portland State University, Department of Mechanical and Materials Engineering, Portland OR, USA
}

As a widely applicable alloying material, zirconium is an essential part of many industries (aerospace, nuclear engineering, precision machining, etc) and is often demanded in high purity. A systematic study was therefore launched in order to combat a trace-level coloration defect discovered in industrial-grade zirconium sponge. The wide variety of morphological features and coloration effects presented by the defect films (iridescent blue/purple, moss/olive green, brown, brick red, golden/straw, etc) which are observed concurrently makes traditional microscopy and spectroscopy an ideal avenue for investigating the composition and formation mechanisms of the films.

Scanning electron microscopy (SEM) imaging shows that the film surfaces are highly topographic and, at the smaller scale, contain microporous features (Fig. 1). Although the surface at this scale also has clearly visible crystalline facets, the surface was largely Raman inactive. Isolated vacancies of the film often exhibited spectra characteristic of monoclinic zirconium oxide (which occurs natively at room temperature). In addition, no Kikuchi lines were observed when investigated with electron back-scatter diffraction (EBSD). Quantitative energy dispersive x-ray spectroscopy (EDS) suggests that the film surfaces have $\mathrm{Zr}: \mathrm{O}, \mathrm{Zr}: \mathrm{Cl}$, and $\mathrm{Zr}: \mathrm{Fe}$ atomic ratios of 100:71, 100:0.37, and 100:0.43, respectively. Conversely, ratios of 100:0.16 and 100:0.36 were observed in the $\mathrm{Zr}$ sponge bulk for $\mathrm{Cl}$ and $\mathrm{Fe}$, respectively (bulk oxygen ratios are erroneous due to the embedding media used in cross-section sample preparation).

X-ray photoelectron spectra (XPS) collected from the film surface (Fig. 2) shows Zr3d and O1s peaks which are indicative of zirconium oxide [1,2]. The Fe2p peaks suggest a Fe ${ }^{+2}$ or $\mathrm{Fe}^{+2 /+3}$ mixed valency [3]. However, determination of possible chlorine-containing compounds such as zirconium or iron oxychloride remains ambiguous due to the overlap of the $\mathrm{Cl} 2 \mathrm{p}$ binding energy near $200 \mathrm{eV}$.

In order to evaluate the distribution of these impurities inside the $\mathrm{Zr}$ sponge, cross-section samples were prepared by resin embedding, thin sectioning, polishing, and carbon coating by evaporation ( $8 \mathrm{~nm}$ ). EDS mapping of cross-section samples (Fig. 3) reveals several principal correlations in the bulk of the material near the film surface: (1) a pitted region begins to arise near the film surface; (2) chlorinecontaining precipitates become finer in size and more evenly distributed; (3) iron-rich bulk regions do not penetrate into these highly-dispersed chlorine regions; (4) oxygen content may also similarly decrease near this region. The ongoing research intends to verify these findings on a larger scale, and identify any causal relationships between these observations and defect film formation.

References:

[1] C Morant et al, Surface Science 218 (1989), p. 331.

[2] D Barreca et al, Surface Science Spectra 7 (2000), p. 303.

[3] M Oku and K Hirokawa, J. Appl. Phys. 50 (1979), p.6303

[4] This project was supported in part by the Oregon Metals Initiative 

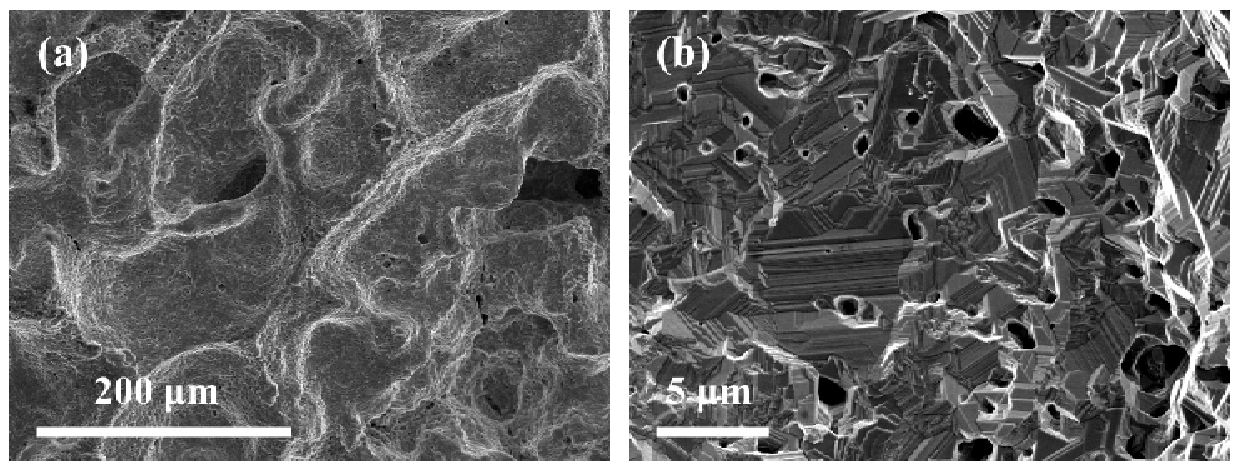

Figure 1. SEM images of film surfaces. (a) $25 \mathrm{kV}$ wide field of view and (b) $5 \mathrm{kV}$ narrow field of view.
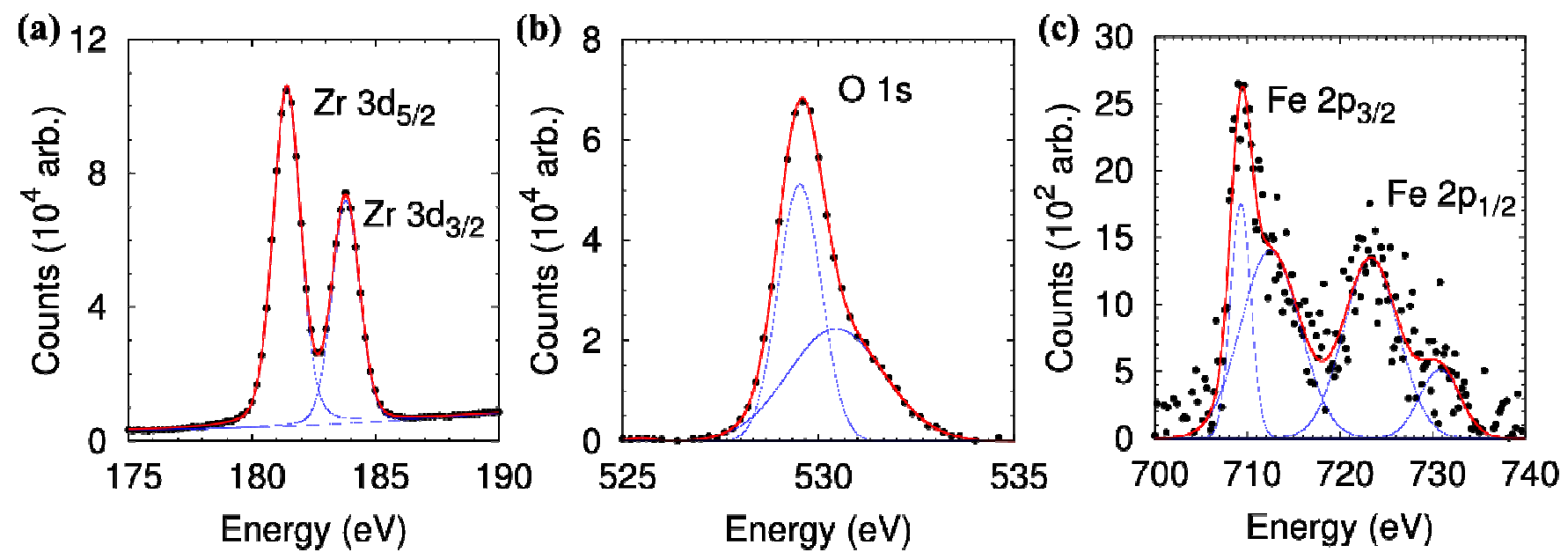

Figure 2. XPS spectra of defect film indicating the (a) Zr3d and background-subtracted (b) O1s and (c) Fe2p peaks.
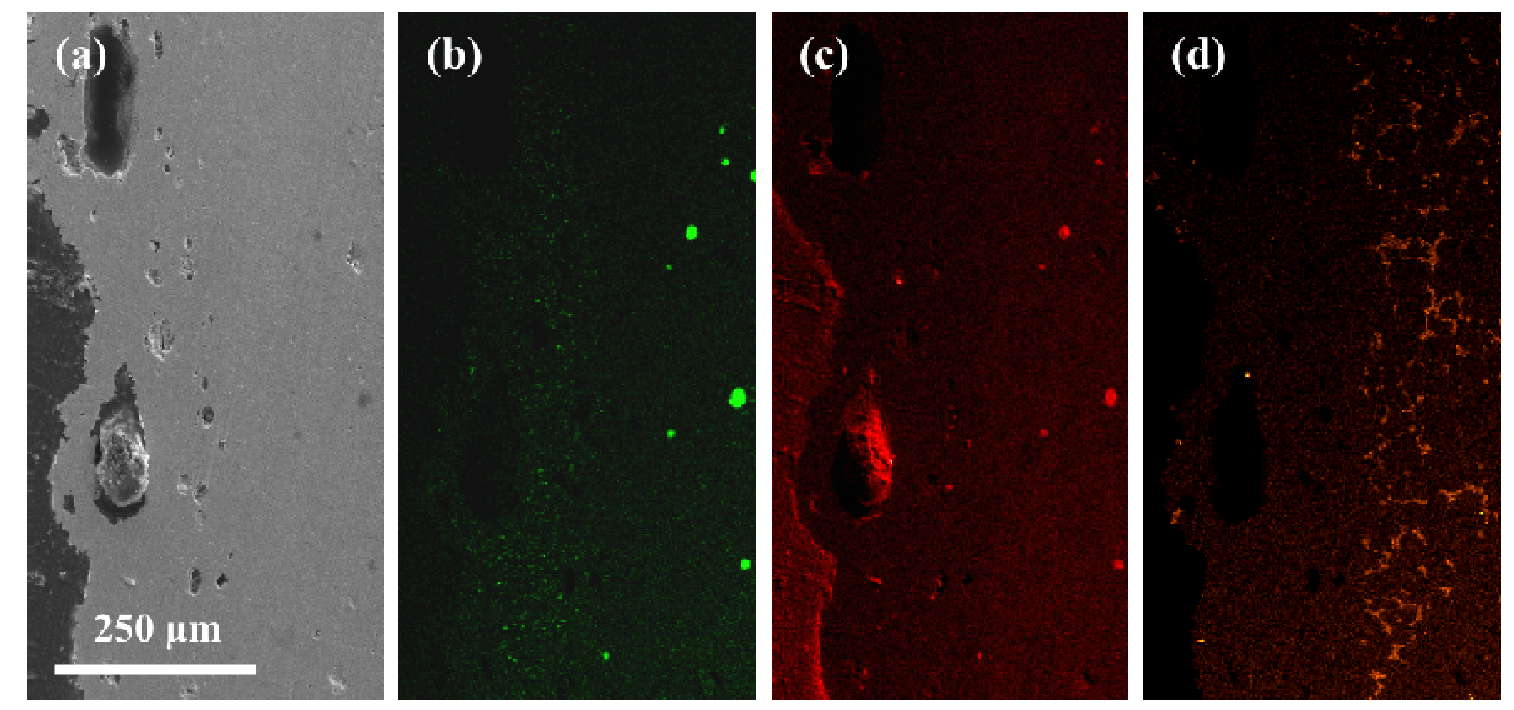

Figure 3. (a) SEM image of embedded cross-section sample and corresponding EDS maps of (b) $\mathrm{Cl} \mathrm{Ka}$, (c) $\mathrm{O} \mathrm{Ka}$, and (d) Fe Ka peaks (all collected at $25 \mathrm{kV}$, film surface is towards the left of each image). 